\title{
LEVANTAMIENTO DE LA CATEDRAL DE PALENCIA
}

Carlos Clemente San Román, Arquitecto

E. A.: Av. Herrera Oria, 167. Madrid-ESPAÑA

Jesús Cantera Montenegro, Prof. de la Universidad Complutense

Fecha de recepción: 19-1V-89

Ficha técnica: Catedral de Palencia

Dimensiones: Longitud total del conjunto catedralicio $127 \mathrm{~m}$.

Ancho

$89 \mathrm{~m}$.

Superficie construida total en planta

$11.303 \mathrm{~m}^{2}$

Superficie del patio claustrado

$702 \mathrm{~m}^{2}$

\section{Cronología constructiva:}

S. VII

- Cripta San Antolín: zona visigótica.

S. XI

- Cripta San Antolin: zona románica.

$1034 \quad-$ Primitiva Catedral románica.

S. XIII 1219

- Conservación Catedral románica.

S. XIV 1321-1 junio - Instalación de la 1. ${ }^{a}$ piedra de la Catedral actual.

S. XV 1420-24 - Maestro Isambart.

1430-65 - Maestro Gómez Díaz de Burgos.

$1443-$ Maestro Pedro Jalop.

1466-1509 - Maestro Bartolomé de Solorzano.

- Rodrigo de Astudillo.

S. XVI 1504-5 - Maestro Martín de Solorzano

1505-16 — - Juán Gil de Hontañón: claustro.

1516 - Finalización de la Catedral.

S. XVIII 1755- - Daños producidos a la Catedral por el terremoto de Lisboa.

1 noviembre

1792

- Restauración del claustro después del terremoto.

S. XIX 1896-1901 - Restauración cabecero: Arquitectos Juán Agapito y Revilla.

S. XX 1911-17 - Restauración de cubiertas y girola: Arquitecto Jerónimo Arroyo.

1980

- Portada Occidental: Arquitecto Fernando Chueca Goitia. 


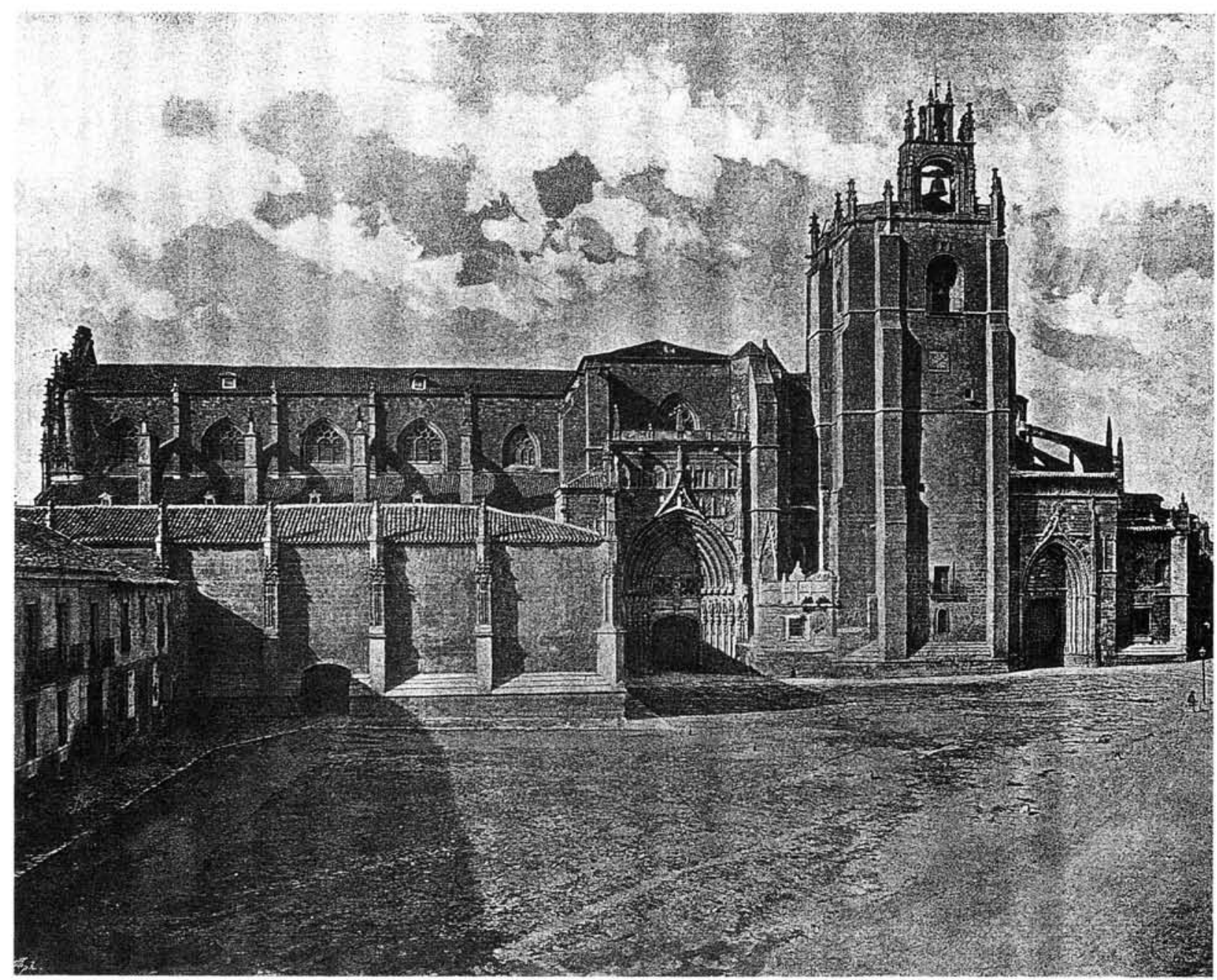

Fotografia de Lauren en "Panorama Nacional"; 1896.

\section{Planimetria de la Catedral de Palencia}

Esta primera planta general de la Catedral de Palencia, levantada por superposición de metrologias (mecáni$\mathrm{ca}$, triangulación y longitudinal), es un primer paso para el conocimiento mecánico exacto de los comportamientos estructurales del monumento. Sobre este plano base se están levantando las secciones y alzados, introduciendo todos los elementos muebles y definiciones constructivas: solados, bóvedas, rejas, sillerias, retablos, etcétera.

El Programa científico elaborado en la actualidad para Palencia se desarrolla desde el año 1986 en el que la Junta de Castilla y León, después de las transferencias (1983) en materia de Patrimonio, comienza las actuaciones de restauración sobre este monumento.

Además de las obras anuales de conservación que se están llevando a cabo con la restauración y reposición de cubiertas, se han iniciado la elaboración y coordinación de los siguientes programas:

(C) Consejo Superior de Investigaciones Científicas Licencia Creative Commons 3.0 España (by-nc)
Arq. Director: Carlos Clemente San Román. Coordinación de la Documentación y Estudios Históricos: Rafael Martinez. Elaboración de listados documentales del Archivo Catedralicio: Santiago Francia, Pilar Luzón, Teresa Carvajal. Inventario-Catálogo general: Jesús Cantera Montenegreo, Cabildo Catedral. Vidrieras: Carlos Muñoz de Pablos. Conservación de la piedra: José M. ${ }^{a}$ Cabrera Garrido. Obras de mantenimiento periódico: Escuela-Taller de Palencia. Además de otros estudios que programarán el mantenimiento a corto y medio plazo del monumento, los Servicios territoriales y la Dirección General del Patrimonio de la Junta de Castilla y León mantienen la supervisión de proyectos y trabajos elaborados, dirigiendo en especial el programa de investigación arqueológica.

\section{Historia de la Catedral}

Durante mucho tiempo la Catedral de Palencia ha sido "Ia bella desconocida", pero afortunadamente hoy en dia, aunque sigue siendo la "bella", y esperemos que con las obras de restauración que ahora se llevan a cahttp://informesdelaconstruccion.revistas.csic.es 
bo aún lo sea más, no es tanto la "desconocida", gracias a que las mejoras de los medios de comunicación y el interés que muestra la sociedad por las cuestio. nes artisticas, la han dado a conocer.

La historia de esta Catedral podemos remontarla, no sólo documentalmente, sino también arquitectónicamente, a muchos siglos atrás, gracias a los interesantes vestigios que nos han llegado en la zona de la cripta, pero que sin embargo aún guardan muchos secretos que mantienen oscuros algunos aspectos de aque. llos tiempos.

Tal vez la cripta entra en relación con la leyenda que nos habla del origen de la Catedral palentina. Según ésta, cierto dia en que el rey de Navarra Sancho Garcés el Mayor perseguia en el curso de una cacería a un jabali, penetró en una cueva en la que se refugió el animal. Cuando el rey se aprestaba a lanzarle la lanza sintió que se le paralizaba el brazo al tiempo que divisaba al fondo de la gruta una imagen, con lo cual comprendió que aquel lugar era sagrado. Suplicó don Sancho recobrar la salud en el brazo y en agradecimiento se comprometió a levantar un templo para dar gloria a Dios y venerar a San Antolin, a quien representaba la imagen de la cueva.

Sea totalmente veridica la leyenda, o esté basada en un hecho real rodeado de un cierto aire legendario, el caso es que fue Sancho Garcés quien restauró la diócesis de Palencia, que tuvo como primer obispo a don Ponce, fallecido en 1035, y fue también el mismo rey quien probablemente se encargó del comienzo de las obras de la iglesia sobre los vestigios visigodos que alli hubiera, y que habrian sufrido graves daños durante la época de la dominación árabe. Este nuevo edificio, comenzado en 1034 en estilo románico, fue arrasado para construir la actual Catedral gótica, quedando escasos recuerdos de él, como son las columnas que aún pueden verse situadas en el exterior de la capilla mayor.

La Catedral gótica vio colocar su primera piedra el día 1 de junio de 1321, siendo entonces obispo de la sede palentina don Juan Fernández de Limia (1321-1330). Las obras discurrieron a ritmo lento, de forma que a principios del siglo XV todavía se cerraba la bóveda de la antigua Capilla Mayor, hoy Capilla del Sagrario. Desde entonces continuó la construcción decidiéndose progresivamente paulatinas mejoras que engrandecieran la Catedral, y es de esta época de la que empezamos a tener constancia de los nombres de los maestros mayores. Así, en el segundo decenio del siglo XV, es el maestro Isambart quien dirige las obras, continuando en esta tarea Gómez Díaz de Burgos y Pedro Palop, siendo a mediados de aquel siglo XV cuando debió de quedar concluida, o casi concluida, toda la fábrica de la cabecera hasta el actual crucero mayor.

(c) Consejo Superior de Investigaciones Científicas Licencia Creative Commons 3.0 España (by-nc)

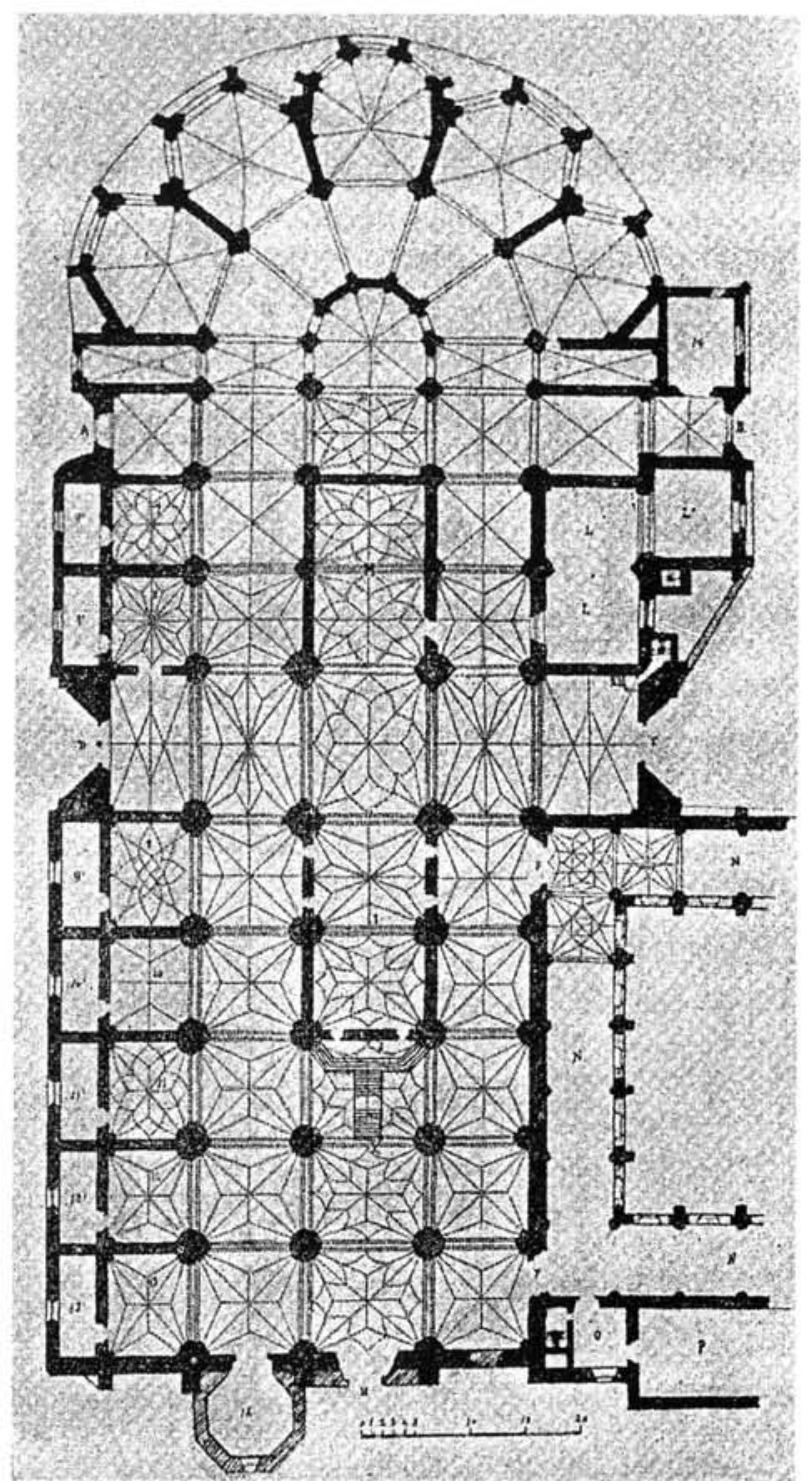

Planta del Arquitecto Juan Agapito publicada en la "Historia de la Ar quitectura Cristiana Española", de V. Lampérez y Romea, 1808.

Durante la segunda mitad del siglo XV se va a dar el impulso definitivo para la conclusión de las obras gracias al esfuerzo de los obispos don Diego Hurtado de Mendoza (1470-1485) y fray Alonso de Burgos (1485-1499), y a la obra de los maestros Bartolomé de Solorzano, Martin de Solorzano, Rodrigo de Astudillo y Juan de Ruesga, quedando concluidas las obras en el año 1516, cuando se finaliza la obra del claustro, construido por Juan Gil de Hontañón, quien lo habia comenzado en 1505.

La planta de la Catedral es de cruz latina, con tres naves y girola con capillas radiales, teniendo rasgos semejantes a las de Burgos y León. Pero tiene además la particularidad de presentar en planta, que no en altura, un falso doble crucero. Esta originalidad no tiene mayor razón de ser que la división, a principios del siglo XVI, de la antigua capilla mayor, de forma que en la actualidad, el extremo occidental de la nave central, http://informesdelaconstruccion.revistas.csic.es 


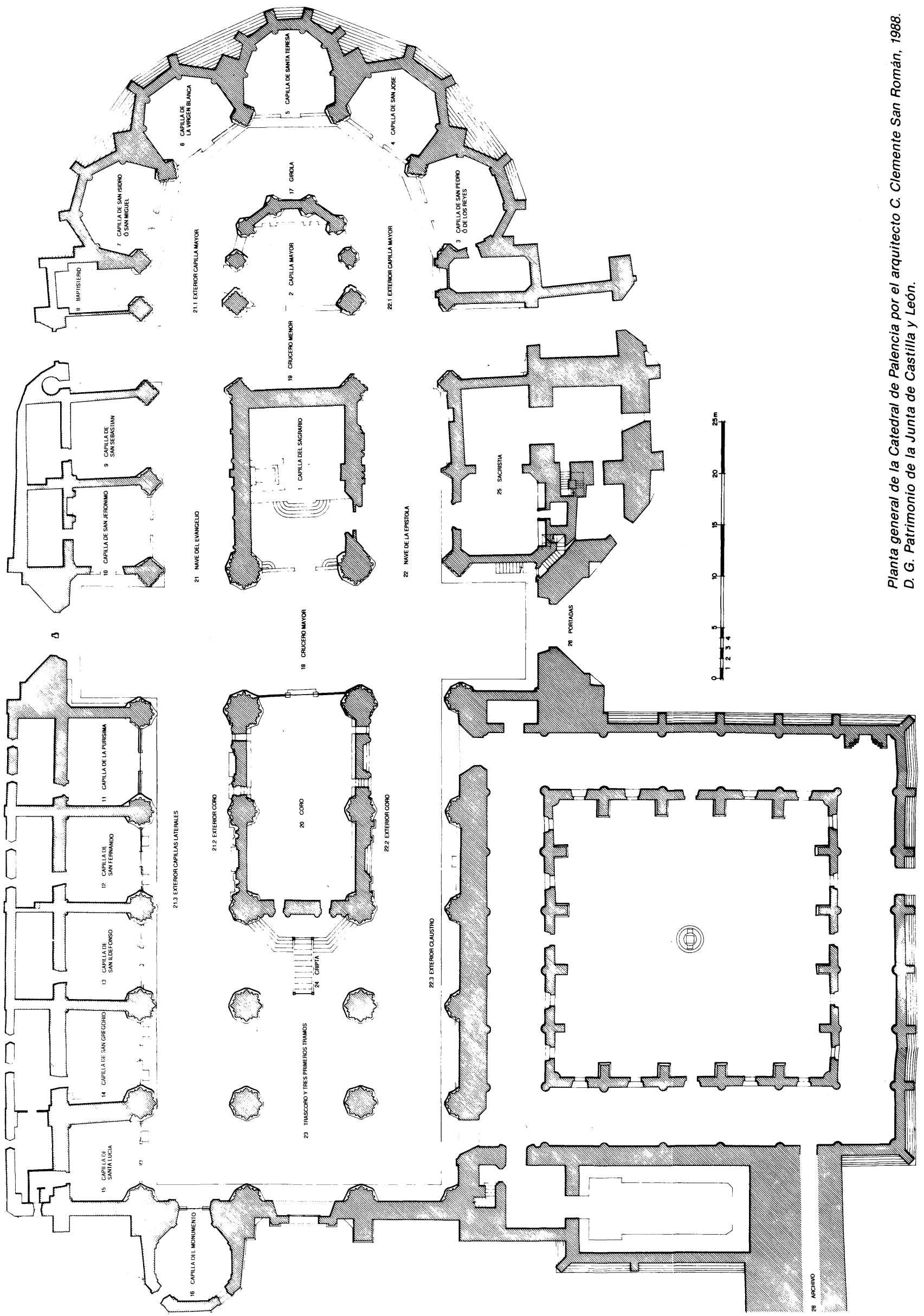

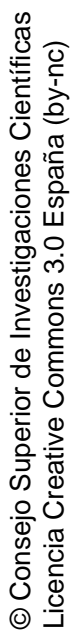



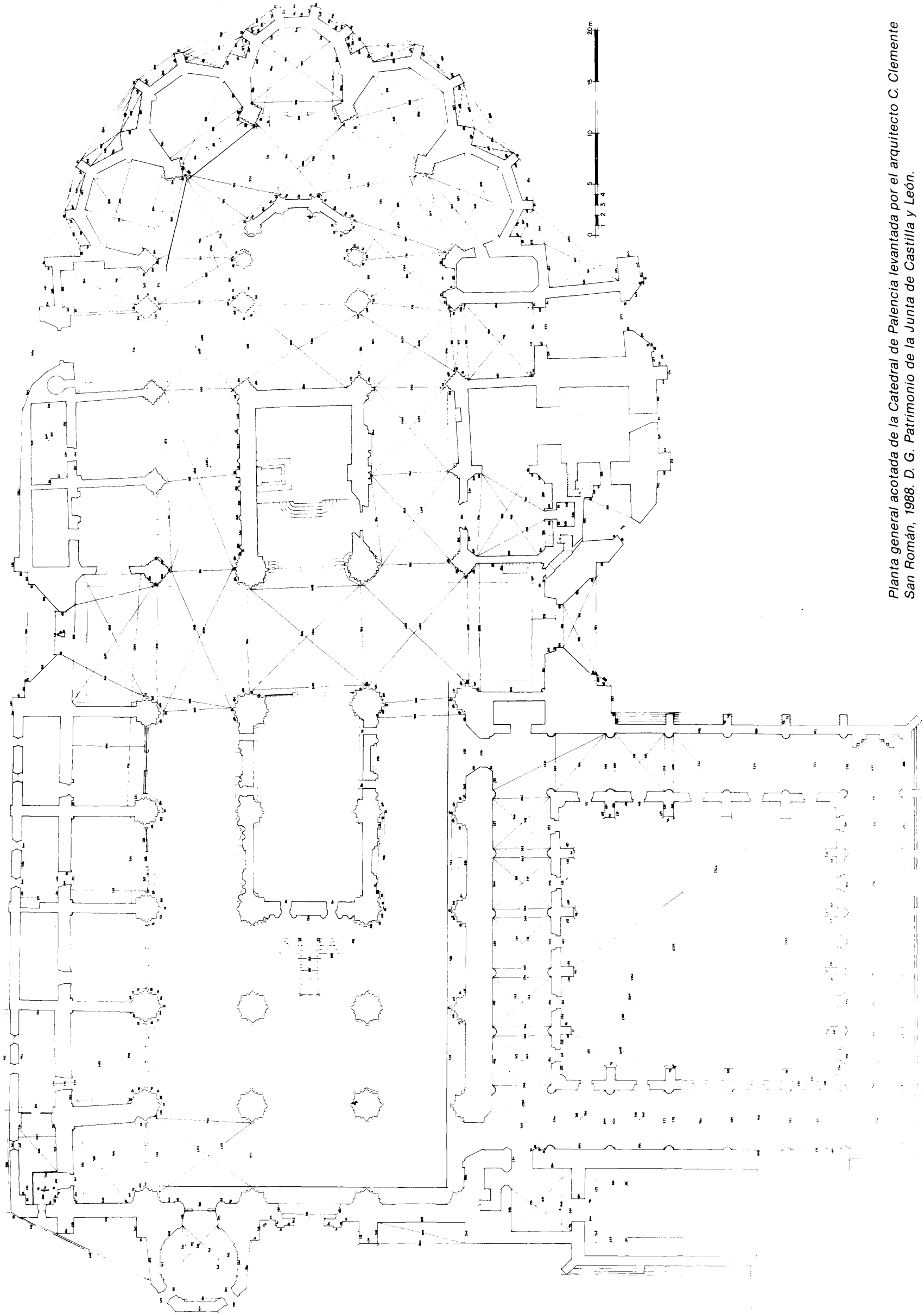


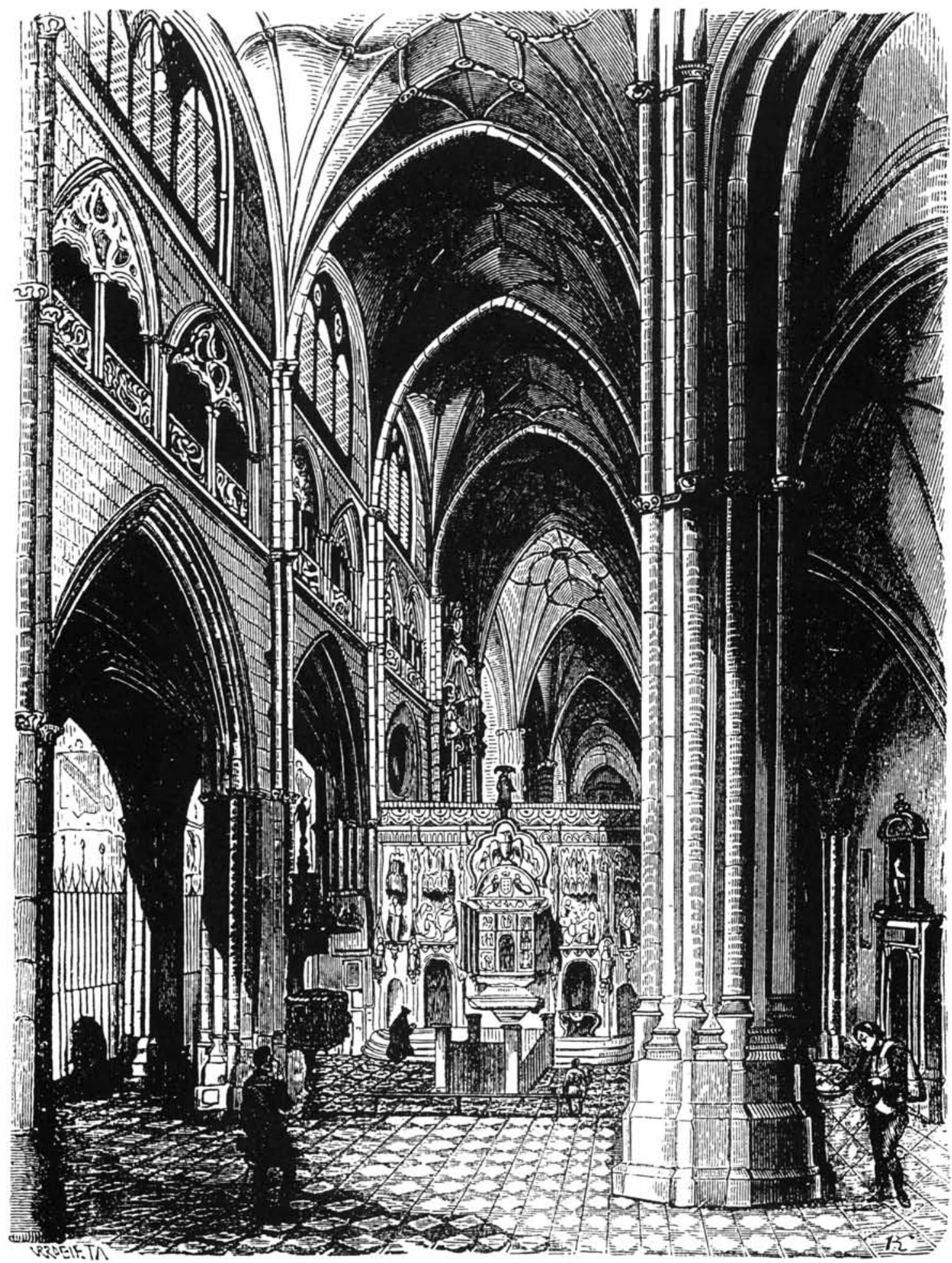

Grabado de Urrabieta publicado en el Libro "Panorama"; 1848.

alrededor del cual irradia la girola, constituye la CapiIla del Sagrario, especie de santuario destinado a guardar el Santísimo Sacramento. Esta condición de lugar más reservado está reforzado por la falsa bóveda que cubre el espacio, y que está muy por debajo de la altura de la verdadera bóveda de la Catedral, de forma que (c) Consejo Superior de Investigaciones Científicas Licencia Creative Commons 3.0 España (by-nc) entre ambas se abre un espacio abierto en el que se desarrolla el mismo esquema constructivo que en el resto del edificio. La actual Capilla Mayor ocupa por su parte los tramos $7 .^{\circ}$ y $8 .^{\circ}$ de la nave central, teniendo su testero plano, con el trasaltar sin ningún tipo de decoración. 
La cabecera, frente a tantas catedrales españolas que la tienen envuelta con construcciones posteriores, mantiene su pureza original, aunque haya tenido que sufrir para ello algunas restauraciones. Tiene esta cabecera girola y siete capillas radiales, de las que las primeras de cada lado son de pianta rectangular y muy estrechas, en tanto que las cinco restantes son poligonales. Dentro de las características de esta zona es interesante el tipo de abovedamiento de los tramos de la girola, pues presentan la tradicional disposición de los nervios descoyuntados, pero al mismo tiempo otros sin descoyuntar, que se enjarjan en los arcos perpiaños de los tramos de la girola; a éstos se agrega un séptimo que une la clave de la bóveda con la del arco formero de la capilla correspondiente.

El resto de las bóvedas de la Catedral son, en las naves laterales de terceletes, y de terceletes con los nervios combados, y en la nave central estrelladas con claves ornamentadas con escudos heráldicos de los obispos que patrocinaron o promovieron las obras, incluyéndose también los de la generosa doña Isabel de Osorio (siglo $X V$ ), que subvencionó buena parte de la construcción, y cuyo bello sepulcro se encuentra en el lateral del lado del Evangelio de la Capilla del Sagrario, realizado en madera policromada y con una inscripción que nos señala que su autor fue el maestro PortiIIo. Descargan las bóvedas por medio de airosos arbotantes dobles, visibles especialmente en la zona de la cabecera.

Muy bello en el conjunto interior de la Catedral es el triforio, que está dispuesto de forma que en cada pared de cada una de las crujias abre un par de vanos en forma de arco apuntado, que a su vez se divide en otro par de arcos escarzanos sobre los que hay una riquísima traceria que hace juego con el pretil de la parte inferior de los vanos.

Exteriormente, la Catedral mantiene en su mayor parte su volumen exento, siendo de destacar en este sentido la zona de la cabecera, que como ya se ha señalado anteriormente está libre de "adherencias", de las que además, las pocas que se pusieron, fueron limpiadas a principios de este siglo, introduciéndose entonces algunas novedades como la terraza sobre las capillas de la girola y unas gárgolas no funcionales, sino de adorno, entre las que destaca por lo anecdótico la que representa a un fotógrafo con la indumentaria y cámara de esa época y que parece estar esperando a que los que pasan por debajo se detengan para ser fotografiados.

La fachada occidental es de austeridad casi cisterciense, pues la calle central está flanqueada por un par de contrafuertes que rematan en pináculos. Entre ellos se abre la portada en la parte inferior, una ventana en forma de arco apuntado en el segundo cuerpo y un piñón con una pequeña rosa en la parte superior, estando re- matado por pináculos que son con los de los contrafuertes la única nota decorativa en este amplio conjunto. Pero la portada de esta fachada nunca llegó a concluirse, tal vez por ser la última parte en construirse de la Catedral, aunque es más seguro que a ello haya contribuido de una forma más importante el que esta zona mira hacia el río, zona despoblada y contraria al asentamiento de la población. Por ello, no ha contado con una portada digna de tal calificación hasta el año 1980 , en que el arquitecto Chueca Goitia realizó la actual, en un estilo netamente clasicista que contrasta vivamen. te con el gótico de la Catedral y que ha sido altamente criticado, aunque habría que señalar que esta actuación se ha debido a la idea de introducir un elemento que dejara señalado de una forma clara que la intervención fue un aditamento posterior, obligado por las circunstancias, y para que por sus formas arquitectónicas puras, esta portada no quedara desvirtuada de la sobriedad general de la fachada.

Otro elemento que también descompone esta fachada es la poligonal capilla del Monumento, que fue añadida en el siglo XVIII sobresaliendo de la línea de la fachada, pero que por otro lado enriquece al conjunto catedralicio al mostrar en su interior un espacio dieciochesco, en un estado bastante bueno de conservación.

El lado septentrional de la Catedral está abierto actualmente a la plaza de Cervantes y en ella destaca la portada de acceso al brazo norte del crucero, la Portada de los Reyes, con un estado lamentable de conservación en la ornamentación gótica, aunque la añadida posteriormente, durante el Renacimiento, se conserva en mejor estado. El lado meridional es el acceso al edificio desde la ciudad, por lo que desde siempre ha sido la zona más cuidada desde el punto de vista de la integración de la Catedral en el urbanismo de la ciu. dad. Allí se abren las puertas de los Novios y la del Obispo, y se forma una recogida plaza, la de la Inmaculada, al estar también cerrada por la adición del claustro al costado de la nave de la Epistola. Son las portadas señaladas de estilo gótico, pero de ellas, la del Obispo, recientemente restaurada, tiene un interesante tímpano con una curiosa iconografía de estilo re. nacentista.

En este lugar se alza también la torre campanario de la Catedral, muy maciza, y con pocos vanos, que contrasta vivamente con la ligereza de los cercanos absidiolos y que no llegó a terminarse, por lo que si tal vez hubiera llegado a tener la airosa aguja proyectada, su imagen habria sido totalmente diferente.

Pieza fundamental de la historia y arquitectura de la Catedral es la cripta de San Antolín. Este testigo de toda la historia de la Catedral se compone en su conjunto de dos partes claramente diferenciadas, pues el primer espacio desde el lugar de descenso, situado ante el 
trascoro de la Catedral, corresponde a un románico muy primitivo, y está formado por cuatro crujias separadas entre si por gruesos arcos fajones, y con arranque de la bóveda casi a ras de suelo. Al fondo hay una última crujia con planta semicircular y con un arco que da paso a la segunda de las partes de que se compone. Ésta es una estrecha nave construida en el siglo VII den. tro del arte visigodo. En el fondo de la nave aún permanecen en pie dos columnas visigodas que soportan tres arquillos en forma de arco de herradura; tras ellos sur. ge la incógnita de lo que se oculte bajo los cimientos de la Catedral, y de la finalidad de este lugar, pues las ventanitas que se abren en sus muros parecen querer apuntar la posibilidad de que la construcción hubiera estado abierta al exterior, cuestión sobre la que hay fuertes controversias, ya que se apunta también la posibilidad de que sea la "confessio" de un edificio des. truido.

Desde el punto de vista arquitectónico de la Catedral, cabria aún citar tres arcos en esviaje por lo poco frecuente de su construcción. Los tres son de estilo renacentista y el más pequeño se sitúa en el acceso a la torre en el brazo sur del crucero; el segundo en el exterior de la Capilla Mayor de la nave de la Epistola, construido con la finalidad de poder observar el altar mayor desde la entrada más importante de la Catedral, esto es, la Puerta del Obispo. Y finalmente el tercero, situado en el primer tramo de la nave de la Epistola, para servir de acceso desde ésta hacia el claustro.

\section{publicaciones del ICCET/CSIC}

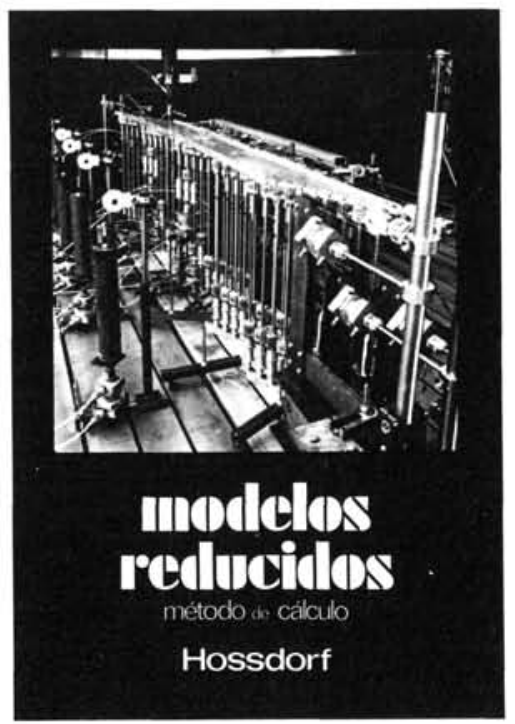

Modelos reducidos. Método de cálculo

H. Hossdorf, Ingeniero Civil

La técnica de los ensayos en modelos reducidos de estructuras sufre hoy dia una decisiva metamorfosis. Hasta hace poco era un medio más bien de artesa. nia, que no siempre era tomado en serio por los académicos teorizantes para comprender el comportamiento resistente de las estructuras complejas y al que se acudió las más de las veces, como a un último remedio debido a sus indiscutibles insuficiencias. Sin embargo, en poco tiempo y gracias a su conexión con los ordenadores digitales, se ha transformado en un instrumento cientificamente valioso. que no puede quedar a un lado en la práctica diaria del Ingeniero Proyectista.

Un volumen encuadernado en cartoné plastificado con lomo de tela, de $17 \times 24 \mathrm{~cm}$, compuesto de 250 páginas, 158 figuras y fotografias.

Precios: 1.800 ptas.; \$ USA 26.00 .

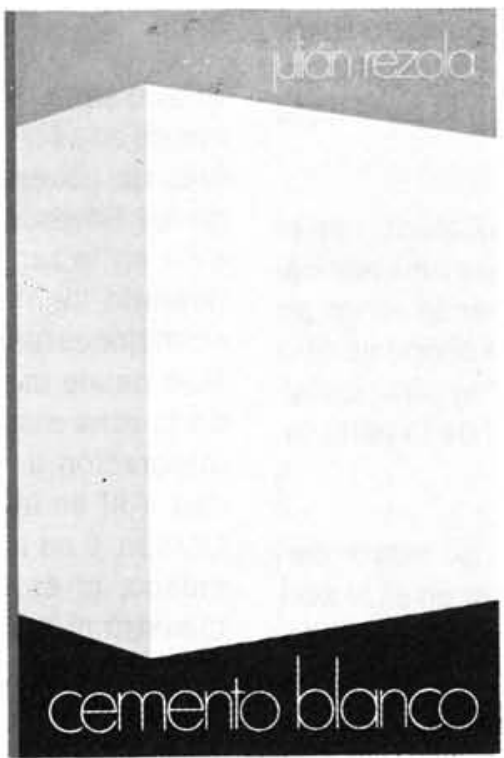

Cemento blanco

Julián Rezola

Ingeniero Quimico Dipl. I. Q. S.

Sabido es que existe una extensa y documentada bibliografia sobre el cemento gris: en cambio, no puede decirse lo mismo acerca del cemento portlan blanco, ya que los escritos existentes se refieren tar sólo a algunas peculiaridades que le distinguen de aquét.

El autor nos ofrece sus profundos conocimientos y su larga experiencia tanto en laboratorio como en fabricación.

La parte descriptiva del libro se complementa con gráficos, diagramas y fotografias de gran utilidad destinados a conseguir la aplicación apropiada de este aglomerante.

Un volumen encuadernado en cartoné policerado, de $17,4 \times 24,3 \mathrm{~cm}$, compuesto de 395 páginas. numerosas figuras, tablas $y$ ábacos.

Precios: España, 1.700 ptas.; extranjero, \$ 24.

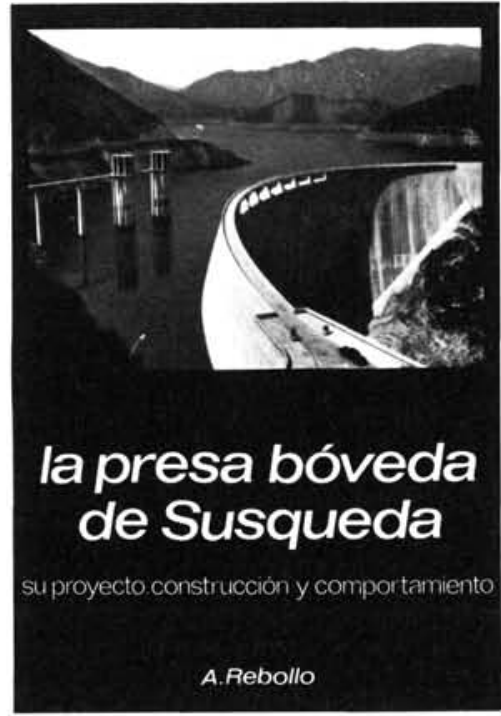

La presa bóveda de Susqueda

A. Rebollo,

Dr. Ingeniero de Caminos

El esfuerzo del constructor de presas se situa por su pretensión de perennidad, a contracorriente de las tendencias de la civilización actual, caracterizada por lo fungible. Pueden evocarse las 10.000 grandes presas en funcionamiento o en construcción que están envejeciendo y reclaman los cuidados gerontológicos para mantener y perfeccionar su servicio y garantizar su inalienable pretensión de perennidad. En la medida en que todas nuevas obras, grandes o pequeñas, son portadoras de riesgos ecológicos y, a veces, catastróficos, que aumentan con el envejecimiento, la gerontologia de las presas es todo un emplazo. La acción adelantada de Arturo Rebollo en este terreno marca un camino a seguir para todos los que aman su propia obra con la devoción paternal que èl ha puesto en Susqueda.

Un volumen encuadernado en cartoné plastificado con lomo de tela, de $18 \times 24,5 \mathrm{~cm}$, compuesto de 408 páginas, 330 figuras y fotografias y 39 tablas.

Precios: 1.700 ptas.; extranjero, \$ USA 24.00 . 